\title{
Extreme neutropenia in glandular fever
}

\author{
HUGH G. PENMAN \\ From Queen Alexandra Hospital, Cosham (Portsmouth and I.o.W. Area Pathological Service)
}

SYNOPSIS Extreme neutropenia has very rarely been recorded as a complication of glandular fever. Two non-fatal cases, with mild secondary infections, are now reported. Extreme neutropenia may in fact be less rare in this disease than it appears to be, but serious illness as a result is exceedingly unusual.

Severe thrombocytopenia has often been recorded in glandular fever (this term being used to mean the same as 'infectious mononucleosis'), and moderate neutropenia is a frequent finding (Carter, 1966; Cantow and Kostinas, 1966). Extreme neutropenia, however, is apparently rare, and Wulff (1965), when recording one case in detail, referred to only five previous reports. Of the three in English, only that by Downey and McKinlay (1923) describes an otherwise typical case of glandular fever, and none of the three papers included results of full differential heterophile agglutination tests. Bernstein (1940) referred to two pre-1930 cases, with neutrophil counts of under 200 per c.mm., that may have been glandular fever, and Lange's (1934) fatal case 3 may have been another. Infection resulting from the extreme neutropenia ( $<200$ per c.mm.) seems to be exceedingly rare, though this may have occurred in Lange's case, and Claveaux, Canzani, and Salveraglio (1943) and Wulff (1965) reported single cases of glandular fever followed within two weeks by extreme neutropenia and infection. ElmenhoffNielsen (1935) reported a possible case of glandular fever followed, two-and-a-half months later, by agranulocytosis and fatal pneumonia. Because of the paucity of previous reports, the following two cases of severe neutropenia, with mild secondary infections, seemed worth recording.

\section{CASE REPORTS}

CASE 1 A 35-year-old female radiographer developed an acute illness with malaise as the dominant symptom. There was no suggestion of excessive exposure to radiation. Four days after onset, she developed mild otitis media which was successfully treated with oral penicillin. After 10 days' illness, the haemoglobin was $12.6 \mathrm{~g} . / 100 \mathrm{ml}$;

Present address: Department of Pathology, University of Otago Medical School, Dunedin, New Zealand.

Received for publication 16 June 1967. total leucocytes 7,000 per c.mm. with $2 \%$ neutrophils (140 per c.mm.), $80 \%$ lymphocytes, $8 \%$ monocytes, $10 \%$ 'smear cells'. Three days later, the leucocyte count was 10,000 per c.mm. $(20 \%$ neutrophils, $64 \%$ lymphocytes, $8 \%$ monocytes); many of the lymphocytes and monocytes were atypical and there were $8 \%$ unclassifiable mononuclear cells. The heterophil agglutination test (H.A.T.) was negative.

During the following month there was a gradual clinical and haematological return to normal. The H.A.T. was positive at a titre of 10 (after guinea-pig kidney absorption) after 17 days' illness, but negative again on two later occasions. Paired sera showed moderately elevated, but not rising, titres against mumps antigens. Serum taken nearly four weeks after onset was negative in the dye test for toxoplasmosis.

CASE 2. A female student aged 18 years presented after nine days of a typical attack of glandular fever. The only drug she had had was erythromycin. Haemoglobin was $11.9 \mathrm{~g} . / 100 \mathrm{ml}$.; total leucocytes 9,300 per c.mm., with $34 \%$ neutrophils, $60 \%$ lymphocytes, $6 \%$ monocytes: many of the latter two types of cell were atypical. The H.A.T. was positive to a titre of 80 after guinea-pig kidney absorption. Staphylococcus pyogenes and $\beta$ haemolytic streptococci were isolated from the throat, both sensitive to erythromycin and tetracycline.

Three weeks after the onset, while the patient was recovering, an area of inflammation, with lymphangitis, developed in the right breast. Similar inflammation appeared the next day in the left axilla. She had never before had such lesions. Oxytetracycline was given and recovery ensued without suppuration. Ten days after the inflammatory lesions appeared, the haemoglobin was $12.5 \mathrm{~g} . / 100 \mathrm{ml}$; ; total leucocytes $4,400 \mathrm{per}$ c.mm. with $2 \%$ neutrophils ( 88 per c.mm.), $2 \%$ eosinophils, $94 \%$ lymphocytes, $2 \%$ monocytes; occasional atypical mononuclears were present. The H.A. Titre was unchanged. The patient was confined to her home, but no further treatment was given. After another week, the leucocyte count was 7,000 per c.mm., with $17 \%$ neutrophils. Three weeks later again the count was 6,700 per c.mm., with $36 \%$ neutrophils; by this time complete clinical recovery had been achieved. 


\section{DISCUSSION}

The incidence of extreme neutropenia in glandular fever may really be comparable to that of severe thrombocytopenia, but the rarity of its discovery is perhaps accounted for by the absence of related symptoms in most cases. In the present case 1 , however, neutropenia may well have been present when the otitis media developed, and in case 2 it seems very likely that the infections were related to neutropenia.

Whether extreme neutropenia in this disease is brought about by the same mechanism as the common mild neutropenia is debatable. Carter (1966) favoured peripheral neutrophil destruction as the cause of the latter, and presumably such destruction could be very severe in a few cases; Cantow and Kostinas (1966) thought that marrow depression occurred. Different mechanisms may operate in different cases. The present two cases may differ between themselves in this respect, for the neutropenia was early in one but late in the other.

Neither of the present patients was admitted to hospital or given steroids, and though both had antibiotics at one stage of the illness, neither received these drugs when the neutrophil count was known to be very low. Both recovered thereafter uneventfully, and the concern felt for these patients at the time hardly seemed in retrospect to be justified.

I am grateful to the general practitioners of the two patients, Drs. V. Martindale and R. J. Thomas respectively, for allowing me to describe these cases. My thanks are also due to Dr. D. G. Fleck for undertaking the test for toxoplasmosis, and to Dr. L. A. Hatch for the virus serology. Certain aspects of case 1 were considered (as case B) in a thesis accepted for the degree of M.D. at Cambridge University.

\section{REFERENCES}

Bernstein, A. (1940). Medicine (Baltimore), 19, 85.

Cantow, E. F., and Kostinas, J. E. (1966). Amer. J. clin. Path., 46, 43. Carter, R. L. (1966). J. clin. Path., 19, 279.

Claveaux, E., Canzani, R., and Salveraglio, F. (1943). Arch. urug. Med., 22, 136.

Downey, H., and McKinlay, C. A. (1923). Arch. intern. Med., 32, 82. Elmenhoff-Nielsen, B. (1935). Acta oto-laryng. (Stockh.), 22, 584. Lange, J. (1934). Norsk Mag. Laegevidensk., 95, 32.

Wulff, H. R. (1965). Scand. J. Haemat., 2, 179. 